\title{
Is the Winograd Technique an Effective Method in the Treatment of Ingrown Toenails among the Pediatric Population?
}

\author{
(D) Murat Celal Sözbilen
}

Ege University Faculty of Medicine, Department of Orthopaedic Surgery, İzmir, Turkey

\begin{abstract}
Aim: This study aimed to examine the results of the Winograd technique applied in the treatment of ingrown toenail cases, which are frequently encountered in childhood, especially in adolescence. The recurrence, satisfaction, and complication rates in pediatric age groups were evaluated with the surgical matrixectomy application of the Winograd technique, a frequently used one in adult age groups.

Materials and Methods: Ingrown toenail cases that had undergone surgical matrixectomy with the Winograd technique between September 2016 and December 2018 were evaluated. Those detected to be stage 2-3 according to the Heifetz classification were operated on. Demographic information was recorded. The cases were divided into three groups as $3-7,7-12$, and $\geq 12$ years as age groups. Such data as recurrence, postoperative infection, osteomyelitis, long term complication and return to regular activity were evaluated. The visual analog scale was used for the satisfaction scale.

Results: A total of 162 operated ingrown toenails from 142 children were followed for an average of 21 months (12-38). The mean age of patients was 13.8 years. When the ingrown toenail location was evaluated, the lateral sides $(98,61.2 \%)$ of the patients were seen to have been affected more. According to age groups, 65\% (105) of the cases were in the group aged 12 years and over. While the frequency of all complications was $8.1 \%$ (13), no chronic complications or osteomyelitis were encountered. Recurrence was observed in $3.1 \%$ of cases and also early infection ( $<15$ days) was observed in 10 cases, while late infection ( $<15$ day) was observed in 3 cases. According to the visual analog scale scores, 135 (95.0\%) cases were found to be satisfactory or very satisfactory.

Conclusion: The Winograd technique (surgical matrixectomy) has low recurrence, low complication and high satisfaction rates in all pediatric age groups even with advanced ingrown toenail complaints. Complete excision of the affected matrix with magnification increases the success of the Winograd technique.
\end{abstract}

Keywords: Pediatric, ingrown toenail, Winograd, matrixectomy, recurrences

\section{Introduction}

Ingrown toenail (onychocryptosis) can be seen frequently in the pediatric population as well as in the adult population (1,2). Especially in the adolescent age group, the failure of the nail bed to fit properly in the nail groove causes inflammation, pain and swelling, leading to lateral and/or medial margin penetration. Wearing tight-fitting shoes, foot plantar pressure disorders (pes planovalgus), foot deformities (clubfoot, hallux valgus) and incorrect short or straight trimming of the nail can lead to cases with this condition. Different from the adult age groups, 
this situation in the pediatric population creates discomfort while conducting school work and sports activities, thus affecting the suffers' success rates $(2,3)$. Psychologically, it affects the relationships of children with their friends. Many children try to treat their ingrown nail on their own, causing the formation of acute infection, suppuration, and granulation tissue.

Recurrence rates have been reported in studies comprising adult age groups in ingrown nail cases, where many means of surgical treatments other than conservative treatments are applied (4). Similar to adults, Heifetz stage 1 cases also benefit from conservative measures (5). In advanced cases where infection, drainage and granulation tissues are encountered, avulsion of the ingrown nail by a surgical procedure and debridement is required. Various surgical techniques are applied in the adult age groups, ranging from simple nail avulsion to germinal matrix excision. Germinal matrixectomy is performed with a sharp excision, while chemicals such as phenol, $\mathrm{NaOH}$ or electrocoagulation can also be applied for matrixectomy $(2,4)$. The pediatric age group, on the other hand, has an immature structure different from that of adults, and results regarding the consequences that such procedures may have in the pediatric group who are still growing are insufficient (1-3).

The Winograd technique was first described in 1929 and is still often the preferred technique (6). The important thing in this technique is the complete avulsion of the germinal matrix in the excised part, which determines recurrence. For this purpose, auxiliary techniques such as phenol or electrocoagulation have been additionally used to disrupt this matrix.

We hypothesized that the use of the Winograd technique without using any matrixectomy tools in addition to surgical matrixectomy might result in better outcomes in the surgical treatment of ingrown toenails. This study aims to evaluate the results of the Winograd technique in the treatment of ingrown toenails among children.

\section{Materials and Methods}

Ingrown toenail cases who were operated on between September 2016 and December 2018 were included in this study. We included children with Heifetz stage 2 or 3 ingrown toenails that had not responded to conservative management. Patients who were followed up for at least 12 months were included. We excluded patients with Heifetz stage 1 ingrown toenails, traumatic nail deformity, dystrophic nail, hemophilia, onycholysis, onychomycosis, immune deficiency, and previously operated recurrent cases (except complete nail avulsion). The patients were divided into 3 groups according to Heifetz classification (5) and those listed in stage 2-3 were operated on.

Data such as age, gender, limb (left or right), ingrown edge (medial or lateral), infection and disease time were recorded. The cases were divided into three groups by age, namely as 3-7 years, $7-12$ years and $\geq 12$ years. All procedures and assessments were performed by the same surgeon (MCS).

All cases underwent conservative therapy with local rifampicin dressing for 3 weeks and first-generation cephalosporin for 7 days before the procedure in the hope that the infection would regress and the short nail or the nail aimed to be removed would grow back (Figure 1).

Surgical procedures (6) were performed by applying digital anesthetic block (2\% lidocaine without epinephrine) and also a digital tourniquet was used. A longitudinal vertical incision was made in the distal of the nail with a sharp-pointed scalpel, starting from $3 \mathrm{~mm}$ proximal to the eponychium, removing 1/4-1/5 of the total nail in the medial or lateral edge of the nail. The application of incision at once advancing down to the matrix prevents additional damage to the nail bed. With a clamp advanced proximal to the germinal matrix from the nail, the involved toenail and germinal matrix were separated and exposed. In order to prevent recurrence, the nail plate and germinal matrix were completely excised and gently scraped with a fine-tipped curette. Following this, the hypertrophic granulation tissue was excised. After abundant irrigation, with sharp tip 2-0 prolene suture (Ethicon ${ }^{\mathrm{TM}}$ ), by first passing the needle from the nail and soft tissue together, then without tying a knot, just passing the needle from the nail in the inferior superior direction, the lip-like soft tissue was ensured to remain under the nail and the knot was left on the nail (Figure 2). Non-compressive dressings were applied and a daily change of the dressing was recommended. Oral antibiotics and non-steroidal anti-inflammatory drugs were given and the stitches were removed after an average of 3 weeks in parallel with the wound healing (Figure 3).
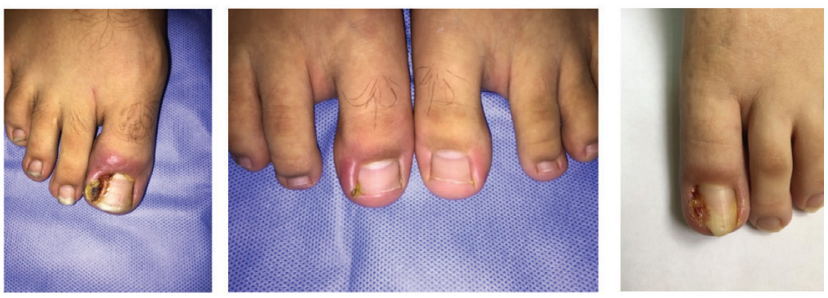

Figure 1. Samples of the severe ingrown toenail. The causes in these samples are including wearing tight-fitting shoes, cutting nails too short, or not cutting the nails straight 
Post-operative local recurrence, complications (including infection), and satisfaction rates were evaluated. While evaluating satisfaction rates after surgical treatment, the patients were asked to respond by considering factors such as feeling of stinging or pain, the ability to wear comfortable shoes, cosmetic appearance, and the ability to keep up with daily activities. For this purpose, with a visual analog scale out of 10 points, a score $\geq 7$ was found to be very satisfactory, 6 or 7 as satisfactory, 4 or 5 as unsatisfactory and if their score was $<4$, the result was found to be very unsatisfactory $(1,4)$. The satisfaction scale was filled in during examinations in follow-ups. This study
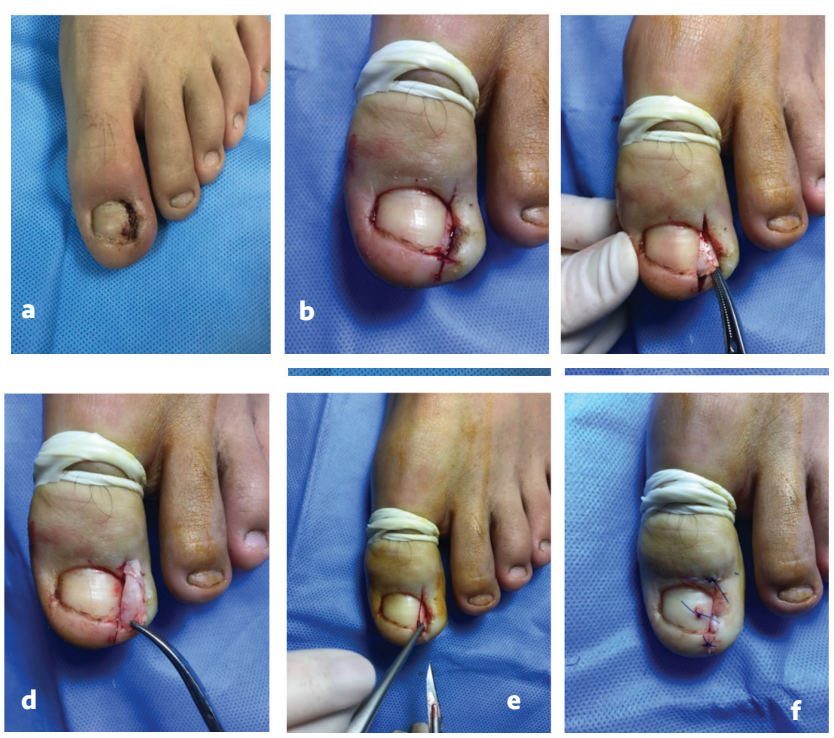

Figure 2. a) 14 years old male lateral edge ingrown toenail, b) Longitudinal incisions were used to perform a wedge resection of the involved lateral edge of the toenail. The incision extended into the eponychium. c) The involved toenail were removed with a clamp placed under the toenail

d) The removed ingrown toenail part is shown in place before operation e) The involved germinal matrix was excised using a surgical lancet f) The external fold of the toe was then approximated to the nail plate with 2-0 Prolene suture
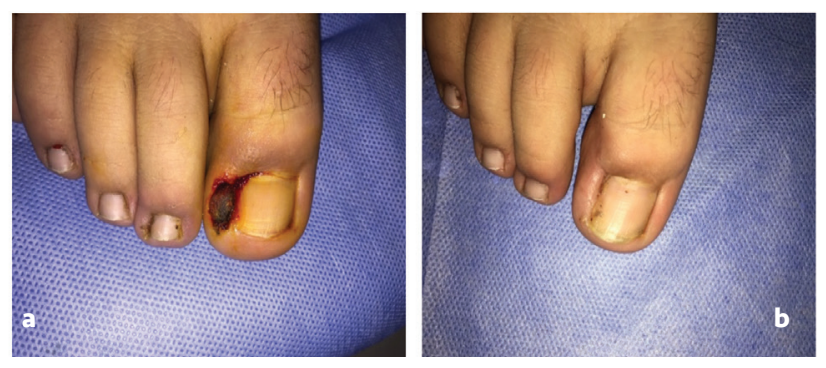

Figure 3. a) 13 years old male Heifetz grade 3 lateral edge ingrown toenail. b) 1 month later from Winograd operation. Lateral edge healed no symptom exist was approved by the ethics committee of Dr. Behçet Uz Child's Disease and Surgery Training and Research Hospital, Local Ethics Committee. Informed consent was obtained from the parents/care givers of the patients.

\section{Results}

The mean age of the 162 ingrown toenail cases of the 142 pediatric patients evaluated was 13.8 years (3-18) and the mean follow-up was 21 months (12-38). The number of cases as well as their demographic data are summarized in Table I. When the ingrown toenail location was evaluated, the lateral side $(98,61.2 \%)$ of the patients were seen to be more affected on both sides. Location features are also given in Table I.

When the cases were analyzed by age groups, it was seen that $65 \%$ (105) of the cases were in the group over $\geq 12$ years of age. While the frequency of all complications was $8.1 \%$ (13), no chronic complications or osteomyelitis were encountered. Recurrence was observed in $3.1 \%$ of cases. Early infection ( $<15$ days) was observed in 10 cases, and late infection ( $\geq 15$ day) in only 3 cases. The process characteristics and results according to age groups are given in Table II.

According to the evaluated visual analogue scale scores of the 142 patients, 135 (95.0\%) cases were found to be satisfactory or very satisfactory, while it was also observed that 7 (5.0\%) patients were unsatisfactory or very unsatisfactory. While 4 of them were the ones who experienced recurrence, the remaining 3 were patients whose regular activity return was delayed due to infection (Table III).

\begin{tabular}{|c|c|c|c|c|}
\hline & & & n (patients) & $\%$ \\
\hline \multirow{2}{*}{\multicolumn{2}{|c|}{ Gender }} & Female & 54 & 28.0 \\
\hline & & Male & 88 & 61.9 \\
\hline \multicolumn{2}{|l|}{ Age in years } & $13.8 \pm 2.8$ & $(3.00-18.00)$ & \\
\hline \multicolumn{2}{|c|}{ Follow-up in months } & 21 & $(12.00-38.00)$ & \\
\hline \multirow{2}{*}{\multicolumn{2}{|c|}{ Heifetz group }} & Stage 3 & 108 & 67.5 \\
\hline & & Stage 2 & 52 & 32.5 \\
\hline & \multicolumn{4}{|c|}{ Side } \\
\hline & & Right & Left & Bilateral \\
\hline \multirow[t]{2}{*}{ Ingrowing edge } & Lateral & $\begin{array}{l}47 \\
(29.3 \%)\end{array}$ & $39(24.3 \%)$ & $12(7.5 \%)$ \\
\hline & Medial & $32(20 \%)$ & $24(15 \%)$ & $6(3.75 \%)$ \\
\hline
\end{tabular}


Table II. Heifetz classification by age groups, complications recurrence and regular activity return results

\begin{tabular}{|c|c|c|c|c|}
\hline & \multicolumn{4}{|c|}{ Age groups } \\
\hline & \multicolumn{2}{|l|}{$3-7$} & $7-12$ & $\geq 12$ \\
\hline $\mathrm{n}$ (patients) & \multicolumn{2}{|l|}{11} & 44 & 105 \\
\hline \multirow{2}{*}{ Heifetz } & Stage 3 & $3(1.8 \%)$ & 31 (19.3\%) & 69 (43.1\%) \\
\hline & Stage 2 & $8(5 \%)$ & $13(8.1 \%)$ & $36(22.5 \%)$ \\
\hline Recurrence & & $0(0 \%)$ & $1(2.27 \%)$ & $4(4.59 \%)$ \\
\hline \multirow{2}{*}{ Infection } & $\begin{array}{l}\text { Early }(<15 \\
\text { days) }\end{array}$ & $\begin{array}{l}1 \\
(0.6 \%)\end{array}$ & $3(1.8 \%)$ & $6(3.7 \%)$ \\
\hline & $\begin{array}{l}\text { Late ( } \geq 15 \\
\text { days) }\end{array}$ & $0(0 \%)$ & $1(0.6 \%)$ & $2(1.2 \%)$ \\
\hline $\begin{array}{l}\text { Long term } \\
\text { complication }\end{array}$ & & $0(0 \%)$ & $0(0 \%)$ & $0(0 \%)$ \\
\hline Osteomyelitis & & $0(0 \%)$ & $0(0 \%)$ & $0(0 \%)$ \\
\hline $\begin{array}{l}\text { Return to } \\
\text { regular activity }\end{array}$ & & $\begin{array}{l}6.8 \\
\text { days }\end{array}$ & 14.5 days & 17.4 days \\
\hline
\end{tabular}

Table III. Patient satisfaction results evaluated by visual analog scale by age groups

\begin{tabular}{|l|l|l|l|l|}
\hline & \multicolumn{4}{l}{ Age groups } \\
\cline { 2 - 5 } & $\mathbf{3 - 7}$ & $\mathbf{7 - 1 2}$ & $\mathbf{2 1 2}$ & Total \\
\hline Very satisfied (8-10) & 9 & 32 & 51 & 92 \\
\hline Satisfied (6-7) & 2 & 11 & 30 & 43 \\
\hline Dissatisfied (4-5) & 0 & 1 & 2 & 3 \\
\hline Very dissatisfied (1-3) & 0 & 0 & 4 & 4 \\
\hline
\end{tabular}

\section{Discussion}

We determined that in the pediatric population of our study, the Winograd method for ingrown toenail results in high satisfaction rates, low recurrence rates, and low complication rates. As we hypothesized, this study indicates that the use of the Winograd technique without using any matrixectomy tools in addition to surgical matrixectomy results in better outcomes and can be considered an excellent modality of treatment of ingrown toenails in the pediatric population.

Ingrown toenail often results in walking difficulties, problems while wearing shoes, and restricted daily activities at work, school, and in the normal course of life (2). It is frequently seen not only in adults but also in the pediatric age group, particularly during the adolescent age. Unlike adults, the age, school status, and psychological status of the child are to be taken into account while deciding the treatment plan. It is important in this sense that the time to return to school and to wear shoes is minimal. While preparing the treatment plan for pediatric groups, Heifetz staging is as important as it is in adults.

In our study, conservative treatment alone was preferred for Heifetz stage 1 patients, whereas recurrence and complications were observed at a low rate in stage 2-3 patients in whom surgery was performed. Heifetz classification has an important place in deciding the treatment method in pediatric age group. Of the 210 cases treated, the stage 1 group of 150 cases were seen to have successfully healed with a conservative treatment plan. In conservative treatment, daily dressing, topical/ oral antibiotics, education on proper nail trimming, and manipulations to separate the corner of the nail from the adjacent soft tissue were applied (7). The timing of conservative treatment is important. If conservative treatment is initiated in advanced cases, a dead-end cycle is expected to occur, the periungual tissue will emerge at the skin corner, thus forming granulation tissue, which can result in inflammation, infection, and foul-smelling discharge (4). This will affect children socially and psychologically as well as leading to a physical strain, all of which will cause failure in school and daily activities (3).

The Winograd method is an effective surgical method based on removing the affected nail edge using wedge resection and removing the partial matrix underneath it and the procedure has low complication rates (8). However, Acar (4) reported 6\% recurrence in his study, while in another study, Aydin et al. (9) reported similarly in 62 patients (6.5\%), Gerristma-Bleeker et al. (10) reported $20.6 \%$, and Kose et al. (11) reported a 13.2\% recurrence rate. In these studies, the high recurrence rates raise questions about the insufficiency of the Winograd technique alone. Traditionally, matrixectomies are performed with a surgical (sharp) excision of the germinal matrix. In spite of the application of matrixectomy, the reason for recurrence is thought to be due to insufficient excision. It was reported that additional procedures such as phenol administration, electrocoagulation or bipolar diathermy reduced recurrence in studies $(2,4,12,13)$. Islam et al. (12), in one of their studies conducted in pediatric cases, reported that $4 \%$ recurrence was observed in chemical matrixectomy with phenol, while a $42 \%$ recurrence rate was seen in surgical matrixectomy. However, in their study, a total of 69 patients were evaluated and the recurrence rate was determined by telephone survey (12). Yang et al. (2), on the other hand, in their study conducted only in the pediatric population, reported a $12 \%$ recurrence rate in 112 children when applying chemical phenolisation. The fact that chemical matrixectomy is 
less dependent on a physician's experience and ability compared to surgical matrixectomy may explain the lower recurrence rate encountered (14). However, Kayalar et al. (15) encountered a $9.8 \%$ recurrence rate with surgical matrixectomy in 224 cases of advanced stage where they did not perform any additional procedures. They emphasized that the procedures should be performed under surgical loupe magnification and that the matrixectomy should be performed completely. In our study, matrixectomy was performed with surgical loupe magnification in the evaluated cases and a 3.1\% recurrence rate was observed. The use of a loupe magnification helps the surgeon work more comfortably and provides a more detailed view especially during matrix excision. Unlike other studies, the evaluation of the pediatric age group alone can also be considered to be effective while achieving this result in terms of the speed and advantage of wound healing observed in the pediatric age group. In addition, chemical matrixectomy methods such as phenol or $10 \% \mathrm{NaOH}$ have some disadvantages. Tissue destruction, apparent drainage, prolonged wound healing, and post-operative infection can be counted as the side effects of these chemicals (2). In recent comparative studies, it has been determined that surgical matrixectomy has lower recurrence rates compared to chemical ones. Akkus et al. (16) reported 3.6\% recurrence in cases where wedge resection was applied, while 5.4\% in chemical matrixectomy with $\mathrm{NaOH}$ and no statistically significant difference was observed. On the other hand, Romero-Pérez et al. (17) reported a recurrence rate of $17.8 \%$ in phenol and matrixectomy in 520 procedures, while the same was $8.2 \%$ in surgical matrixectomy, and no difference between overall satisfaction rates was reported to have been seen (17).

In our study, while a total of $13(8.1 \%)$ infections were observed, 10 of them were seen in the early period, and 3 in the late period. All of the cases were observed to heal. In studies conducted in adults, Peyvandi et al. (18) reported a $6 \%$ infection rate in 50 patients. Yang et al. (2), on the other hand, reported a $9 \%$ infection rate in the pediatric population in the early period. In our study, the rates show similarity in terms of rates of infection with the rates of those undergoing surgical matrixectomy $(2,18)$. Also, similar infection rates have been reported in studies in which matrixectomy was performed with chemical or electrocoagulation (source electrochemical). Infection treatment response was seen to be good in children and osteomyelitis was not observed. The fact that these infections were not complicated can be explained by routine pre-and post-operative oral antibiotic therapy provided and dressings applied twice a day, which was recommended to the patients. This situation can also be explained by the fact that children have an advantage in terms of wound healing. We are also of the opinion that detailed granuloma extraction and infective tissue debridement performed with the use of loupe magnification mentioned by Kayalar et al. (15) have a positive effect on the process.

It was witnessed that the satisfaction rates pertaining to the procedure were very high for patients. 95\% of the patients were found to be very satisfied or satisfied. This situation of our cases was similar to the satisfaction rates expressed in similar studies $(4,11)$. This determining factor of basic satisfaction obtained in pediatric age groups was associated with the desire of children to return to activity quickly and to be able to wear shoes as soon as possible. It was observed that the main reason of almost all of the cases indicating dissatisfaction was in those cases where recurrence was reported. The early recovery period of cases is also what determines the satisfaction level of the sufferers. For this reason, pre-and post-operative detailed information about the process ensures that the expectations are not higher than what is to be expected and the level of subsequent satisfaction may increase afterward.

\section{Study Limitations}

The limitations of this study were the absence of a control group; however, our aim was to evaluate the results of the Winograd technique in children and adolescents. Our analysis is not therefore necessarily affected by the lack of a control group. Nevertheless, a control group would have provided an opportunity to observe the differences between chemical or electrocoagulation matrixectomy and the Winograd technique. Secondly, this is a retrospective single-center study with all the restrictions associated with such studies. All procedures and assessments were performed by a single surgeon so that could be a potential source of bias.

\section{Conclusion}

The Winograd technique has low recurrence, low complication, and high satisfaction rates in pediatric age groups with advanced (Heifetz 2-3) ingrown toenails. According to our results, it may be suggested that the use of the Winograd technique with detailed surgical matrixectomy using magnification and meticulous wound care results in better outcomes and can be considered an effective modality of treatment of ingrown toenails in the pediatric population. 


\section{Ethics}

Ethics Committee Approval: This study was approved by the ethics committee of Dr. Behçet Uz Child's Disease and Surgery Training and Research Hospital Local Ethics Committee (date: 11.03.2021, number: 2021/05-13).

Informed Consent: Informed consent was obtained from the parents/care givers of the patients.

Peer-review: Externally peer-reviewed.

Financial Disclosure: The author declared that this study received no financial support.

\section{References}

1. Haricharan RN, Masquijo I, Bettolli M. Nail-fold excision for the treatment of ingrown toenail in children. I Pediatr 2013; 162:398-402.

2. Yang G, Yanchar NL, Lo AY, Jones SA. Treatment of ingrown toenails in the pediatric population. I Pediatr Surg 2008; 43:9315.

3. Ezekian B, Englum BR, Gilmore BF, Kim J, Leraas H), Rice $\mathrm{HE}$. Onychocryptosis in the pediatric patient: review and management techniques. Clin Pediatr (Phila) 2017; 56:109-14.

4. Acar E. Winograd method versus winograd method with electrocoagulation in the treatment of ingrown toenails. / Foot Ankle Surg 2017; 56:474-7.

5. Heifitz C). Ingrown toenail-a clinical study. Am I Surg 1937; 38:298-315

6. Winograd AM. A modification in the technic of operation for ingrown toe-nail. 1929. I Am Podiatr Med Assoc 2007; 97:274-7.

7. Lazar L, Erez I, Katz S. A conservation treatment for ingrown toenails in children. Pediatr Surg Int 1999; 15:121-2.

8. Richardson EG, Hendrix CL. Disorders of nails and skin. In: ST Canale, (ed). Campbell's Operative Orthopedics, 10th ed. Philadelphia, Mosby-Elsevier, 2003; 4171-87.
9. Aydin N, Kocaoglu B, Esemenli T. Partial removal of nail matrix in the treatment of ingrowing toe nail. Acta Orthop Traumatol Turc 2008; 42:174-7.

10. Gerristma-Bleeker CL, Klaase JM, Geelkerken RH, Hermans ), van Det RJ. Partial matrix excision or segmental phenolization for ingrowing toenails. Arch Surg 2002; 137:320-5.

11. Kose O, Guler F, Gurcan S. Cosmetic results of wedge resection of nail matrix (Winograd technique) in the treatment of ingrown toenail. Foot Ankle Spec 2012; 5:241-4.

12. Islam S, Lin EM, Drongowski R, et al. The effect of phenol on ingrown toenail excision in children. I Pediatr Surg 2005; 40:290-2.

13. Farrelly PJ, Minford J, Jones MO. Simple operative management of ingrown toenail using bipolar diathermy. Eur / Pediatr Surg 2009; 19:304-6.

14. Herold N, Houshian S, Riegels-Nielsen P. A prospective comparison of wedge matrix resection with nail matrix phenolization for the treatment of ingrown toenail. J Foot Ankle Surg 2001; 40:390-5.

15. Kayalar M, Bal E, Toros T, Özaksar K, Gürbüz Y, Ademoğlu Y. Results of partial matrixectomy for chronic ingrown toenail. Foot Ankle Int 2011; 32:888-95.

16. Akkus A, Demirseren DD, Demirseren ME, Aktas A. The treatment of ingrown nail: chemical matricectomy with $\mathrm{NAOH}$ versus wedge resection. Dermatol Ther 2018; 31:e12677. doi: 10.1111/dth.12677.

17. Romero-Pérez D, Betlloch-Mas I, Encabo-Durán B. Onychocryptosis: a long-term retrospective and comparative follow-up study of surgical and phenol chemical matricectomy in 520 procedures. Int J Dermatol 2017; 56:221-4

18. Peyvandi H, Robati RM, Yegane RA, Hajinasrollah E, Toossi P, Peyvandi AA. Comparison of two surgical methods (Winograd and sleeve method) in the treatment of ingrown toenail. Dermatol Surg 2011; 37:331-5. 